\title{
A leitura das horas no material didático do projeto Educação Matemática nos anos iniciais
}

\author{
Wagner Marcelo Pommer ${ }^{1}$ \\ Mariana Chiccolli Pereira de Rezende ${ }^{2}$
}

\begin{abstract}
Resumo
Esta pesquisa objetivou verificar se, como e em que medida as atividades do material didático denominado Projeto EMAI promovem condições para o aprendizado da leitura de horas no 1 o ano do ciclo inicial do Ensino Fundamental. O referencial teórico se situou na Base Nacional Comum Curricular (Brasil, 2017) e na proposta construtivista. A pesquisa documental verificou que as duas atividades didáticas propostas no projeto EMAl possibilitaram a mobilização de conhecimentos cotidianos e conteúdos procedimentais, o que pode acessar a zona de desenvolvimento proximal dos alunos (Vygotsky, 1984; 1987). Observamos a quase ausência da História da Matemática como suporte didático e o favorecimento dos conteúdos conceituais, conforme Coll (1996), em detrimento de atividades de essência manipulativa.
\end{abstract}

Palavras-chave: Tempo; Medida; Projeto EMAl; Ensino Fundamental.

The reading of hours in the didactic material of the Mathematical Education project in the early years

\section{Abstract}

This research aimed to verify if, how and to what extent the activities of EMAl's Project promote conditions for learning to read time in the first year of Elementary School. The theoretical framework was based on the Common National Curricular Base (Brazil, 2017) and the constructivist proposal. The documentary research found that the two didactic activities proposed in the EMAl's project enabled the mobilization of spontaneous knowledge and procedural contents, which can access the students' proximal development zone (Vygotsky, 1984; 1987). We observe the almost absence of the History of Mathematics as didactic support and the favoring of conceptual contents, according to Coll (1996), to the detriment of activities of manipulative essence.

Keywords: Time; Measure; EMAI Project; Elementary School.

\section{Introdução}

$\mathrm{Na}$ instituição escolar o estudo da grandeza 'tempo' permeia as diversas etapas da escolaridade básica, desde os anos iniciais do Ensino Fundamental, fato destacado nos Parâmetros Curriculares Nacionais do Ensino Fundamental de Matemática (Brasil, 1997) e na Base Nacional Comum Curricular (Brasil, 2017).

A noção de tempo, em um contexto cultural mais antigo, era impregnada de significações mágico-religiosas, como a história de Homero na:

\footnotetext{
${ }^{1}$ Universidade Federal de São Paulo, Diadema. wagner.pommer@unifesp.br

${ }^{2}$ Rede Pública do Estado de São Paulo, São Paulo. chiccolli@prof.educacao.sp.gov.br 
[...] Mitologia Grega, quando Zeus se apodera do lugar de Chrónos, Deus do Tempo, e fica, assim, a ter o domínio sobre as questões temporais. Para os antigos, o Sol, a Lua e o Dia, a Noite e o Sono são divindades mitológicas responsáveis pela marcação do tempo, e são responsáveis pela interpretação dos fenômenos na natureza (SANTOS, 2016, p.53).

Porém, o conceito de tempo é complexo. Hall (1996 apud SANTOS, 2016) aponta que a grandeza 'tempo' situa um agregado de conceitos, fenômenos e ritmos que envolvem uma ampla realidade. Na sociedade moderna, Husti (1992 apud SANTOS, 2016) salienta que o tempo adquire várias facetas como o metatempo, o tempo biológico, o tempo individual, o tempo físico, o tempo metafísico, o microtempo, o tempo sagrado e o tempo profano, dentre outros.

A prática de medir o tempo surgiu nas antigas civilizações devido às questões que envolviam rituais religiosos e ao plantio, pois esta atividade se baseava nas estações do ano para o controle das colheitas e semeaduras.

Santos (2016) relembra que o relógio de pêndulo de Galileu foi um marco de quantificação temporal na era renascentista, que desencadeou as teorias mecânicas de Newton e a relatividade de Einstein. Atualmente, a leitura de horas e minutos em relógios digitais e analógicos está presente no nosso cotidiano em diferentes situações e necessidades do ser humano.

Neste sentido, este trabalho objetivou verificar se, como e em que medida as atividades do Projeto EMAI promovem condições para o aprendizado da leitura de horas no $1 \stackrel{0}{\circ}$ ano do ciclo inicial do Ensino Fundamental.

\section{Pressupostos Teóricos}

Para verificar as contribuições do material didático do Projeto Educação Matemática nos Anos Iniciais (EMAI) para o aprendizado da leitura de horas no primeiro ano do ciclo inicial partimos de alguns pressupostos construtivistas, vínculo apontado em Simon (1995).

Segundo Piaget (1975), a noção de tempo se inicia para o aluno a partir dos seis ou sete anos. Ao alcançar a idade escolar, começam a ser inseridas pequenas responsabilidades, como a hora de dormir, a duração das aulas, a hora para se alimentar, dentre outras demandas do mundo infantil, que podem e devem ser exploradas no terreno da Educação.

Nogueira (2006) aponta que o conceito de medida em Piaget está ligado a noção de 
conservação, de modo que mudanças na forma ou disposição de certos objetos não produzem alterações nos atributos mensuráveis, como é o caso do tempo.

Para Caraça (1970), medir é comparar uma grandeza com certa unidade e, ainda, há a necessidade de expressar o resultado do ato de medir por meio de um número adequado.

No ambiente escolar, Nogueira (2006) destaca que as primeiras atividades de medição deveriam se basear na comparação de objetos. No caso do tempo, Nogueira (2006) propõe que as atividades com as crianças se situem em um entorno familiar, de forma direta por meio da comparação de intervalos de tempo e, posteriormente, no decorrer dos anos da instituição escolar de forma indireta. Na comparação indireta a autora propõe o apoio de um terceiro objeto, que remeta a propriedade transitiva.

As diversas situações de exploração deverão fazer com que o aluno perceba que o valor da medida depende da unidade escolhida e que essa unidade deverá ser escolhida e/ou definida para cada situação concreta. É assim particularmente importante guiar os alunos na descoberta da necessidade de utilização das unidades convencionais (NOGUEIRA, 2006, p.74).

A autora menciona a relação parte-todo, pois a aplicação recorrente de uma unidade padrão para efetivar medidas pressupõe que a criança interiorize que o todo é constituído por partes de igual tamanho (a unidade padrão) e, com a replicação da menor unidade, pode-se reconstituir o todo, o que contribui para a construção de um sistema de medida.

Deste modo, os materiais didáticos que façam um trabalho com a medição do tempo devem conter propostas onde o aluno seja capaz de:

[...] selecionar, de maneira adequada e autônoma, os instrumentos de medida e de realizar corretamente o processo, indicando o resultado dessa experimentação. Prevê-se também a utilização de instrumentos de medição utilizados na vida corrente, nomeadamente calendários, horários e relógios, proporcionando-se dessa forma excelentes oportunidades de articulação com vivências do dia a dia do aluno (NOGUEIRA, 2006, p.75).

A Base Nacional Comum Curricular (BNCC), descrita em Brasil (2017), é um documento do Ministério da Educação e Cultura que incorporou alguns pressupostos discutidos por teóricos de diversas correntes educacionais. Este documento descreveu as aprendizagens essenciais que 
todos os alunos devem desenvolver ao longo de cada etapa da educação básica, indicando os conhecimentos necessários assim como as competências associadas a cada tema de matemática elementar do currículo brasileiro.

Neste ínterim, destacamos no referido documento a proposta de contextualização dos conteúdos, onde estão identificadas as estratégias para apresentá-los e torná-los significativos, em face de metodologias e estratégias didático-pedagógicas adequadas e que permeiam o mundo físico, social e cultural que permitam entender e explicar a realidade.

Com relação ao tópico ‘Espaços, tempos, quantidades, relações e transformações', a Base Nacional Comum Curricular (BNCC) salienta que o aluno deverá:

- Utilizar vocabulário relativo às noções de grandeza (maior, menor, igual etc.), espaço (dentro e fora) e medidas (comprido, curto, grosso, fino) como meio de comunicação de suas experiências.

- Resolver, criar e registrar situações-problema do cotidiano e estratégias de resolução.

- Utilizar unidades de medida (dia/noite, dias/semanas/meses/ano) e noções de tempo (presente/passado/futuro, antes/agora/depois), para responder a necessidades e questões do cotidiano.

- Identificar e registrar quantidades por meio de diferentes formas de representação (contagens, desenhos, símbolos, escrita de números, organização de gráficos básicos) (BRASIL, 2017, p.51).

Especificamente, o quadro 01 indica as habilidades para a medida do tempo presentes no texto da Base Nacional Comum Curricular (BNCC).

Quadro 01: Habilidades relativas ao 10 ano do Ensino Fundamental para as medidas de tempo.

\begin{tabular}{|l|l|}
\hline \multicolumn{1}{|c|}{ Objetos do conhecimento } & \multicolumn{1}{c|}{ Habilidades } \\
\hline $\begin{array}{l}\text { Medidas de tempo: unidades de } \\
\text { medida de tempo, suas relações e } \\
\text { o uso do calendário. }\end{array}$ & $\begin{array}{l}\text { (EF01MA16) Relatar em linguagem verbal ou não } \\
\text { verbal sequência de acontecimentos relativos a um dia, } \\
\text { utilizando, quando possível, os horários dos eventos. } \\
\text { (EF01MA17) Reconhecer e relacionar períodos do dia, } \\
\text { dias da semana e meses do ano, utilizando calendário, } \\
\text { quando necessário. } \\
\text { (EF01MA18) Produzir a escrita de uma data, } \\
\text { apresentando o dia, o mês e o ano, e indicar o dia da } \\
\text { semana de uma data, consultando calendários. }\end{array}$ \\
\hline
\end{tabular}

Fonte: Adaptado de BRASIL (2017, p.237). 
O referido documento propõe que os conhecimentos devem estar atrelados ao desenvolvimento de competências gerais que se espera ao longo da escolaridade básica (Brasil, 2017).

Para Perrenoud (1999), o que se espera como cerne da instituição escolar é que esta não deva enfatizar conteúdos, mas preparar - todos - para a vida em uma sociedade moderna, tendo como meta formar indivíduos competentes.

Para Perrenoud (1999), as competências estão ligadas a contextos culturais, profissionais e condições sociais. O autor destaca que a escola se preocupa mais com certos ingredientes e, bem menos, em promover competências em sinergia com situações complexas. Diz o autor que a escola deve ir muito além dos famosos 'três erres' dos anos 50 - Read, wRitingandcompRehend (ler, escrever e contar) - proporcionando condições aos estudantes de desenvolver as capacidades de raciocinar, explicar, resumir, observar, comparar, desenhar e outras dúzias de capacidades gerais.

Perrenoud (1999) complementa que a escola deveria se empenhar em promover a transferência e a mobilização de conteúdos e competências. O autor considera que a abordagem por competências é uma maneira de levar a sério uma problemática antiga, que ressaltava a necessária transferência de conhecimentos como forma de desenvolver a capacidade de utilizar diferentes recursos e utilizá-los para a resolução de problemas. Ensinar, para Perrenoud (1999), deveria consistir em conceber, encaixar e regular situações de aprendizagem, seguindo os princípios pedagógicos ativos construtivistas.

O Currículo do Estado de São Paulo apresenta propostas para auxiliar o professor em sua prática docente. A Secretaria da Educação do Estado de São Paulo desenvolveu, em 2008, por meio da Coordenadoria de Gestão da Educação Básica, um currículo base para o Ensino Fundamental e Ensino Médio das escolas paulistas, expresso em São Paulo (2008b).

Com essa ação, a Secretaria da Educação do Estado de São Paulo criou uma base comum de habilidades e competências a serem trabalhadas pelo corpo docente das Unidades Escolares, buscando o pleno desenvolvimento do aluno em uma rede de ensino estruturada e articulada para todos no âmbito educacional.

Para o ensino de Matemática isto foi viabilizado através de uma coleção de material didático denotado por EMAI, que designa o Projeto de Ensino de Matemática nos Anos Iniciais, conforme descrito em São Paulo (2013). 
Por sua vez, as competências podem ser desdobradas em um conjunto de habilidades. No material da rede pública paulista a habilidade de identificar as horas e os minutos é desenvolvida por meio de atividades diversas preparadas para serem desenvolvidas durante os cinco primeiros anos do Ensino Fundamental. Este material se insere nos pressupostos da abordagem construtivista, onde o processo educacional deve:

[...] provocar situações que sejam desequilibradoras para o aluno, desequilíbrios esses adequados ao nível de desenvolvimento em que a criança vive intensamente (intelectual e afetivamente) cada etapa de seu desenvolvimento. Um ensino que procura desenvolver a inteligência deverá priorizar as atividades do sujeito, considerando-o inserido em uma situação social (MIZUKAMI, 1986, p.70).

Neste contexto construtivista, os estudos e pesquisa da proposta sociointeracionista de Vygotsky (1984) considera importante que as crianças sejam vistas como sujeitos ativos, que participam e interajam com o que acontece ao seu redor.

Vygotsky (1987) aponta que a formação de conceitos depende da interação de dois tipos de conceitos: os espontâneos e os científicos. Os conceitos espontâneos são aqueles adquiridos por experiência pessoal, concreta e cotidiana das crianças.

Em oposição aos conceitos cotidianos, os conceitos científicos são aqueles que não são acessíveis por meio da pura observação ou manipulação direta pela criança, sendo necessária uma intervenção direta do membro intelectualmente mais maduro do grupo social. Os conceitos científicos "[...] são os conhecimentos sistematizados, adquiridos nas interações escolarizadas" (VYGOTSKY, 1984, p.77).

Outro aporte de Vygotsky (1987) se refere a Zona de Desenvolvimento Proximal ou Potencial (sigla ZDP), conceito elaborado pelo pesquisador como sendo a distância entre o nível de desenvolvimento real,este determinado pela capacidade de resolver um problema sem ajuda de outros e o nível de desenvolvimento potencial, que é determinado através de resolução de atividades sob a orientação de um membro mais maduro do grupo social.

Atualmente, o ato de ensinar na escolaridade básica não pode se limitar somente aos conteúdos, aqueles que se referem a dados e fatos expressos nas diversas disciplinas do currículo ou nos manuais de ensino. 
Nos anos iniciais do Ensino Fundamental, a responsabilidade pela formação do cidadão é primordial, tendo em vista a necessidade de construir bases sólidas para que futuramente o ser possa interagir em sociedade de maneira participativa e crítica.

Os cadernos didáticos do Projeto EMAI são constituídos por oito Trajetórias Hipotéticas de Aprendizagem (THA) compostas por sequências distribuídas em cinco volumes. Segundo Simon (1995), as Trajetórias Hipotéticas de Aprendizagem se referem à maneira que o professor planeja o caminho da aprendizagem, com base no conhecimento construído, o que pode contribuir para uma aprendizagem significativa. A trajetória hipotética representaria:

[...] a previsão do professor como um caminho pelo qual a aprendizagem pode ocorrer. É hipotético porque a trajetória real de aprendizagem não é conhecida previamente. Ela caracteriza uma tendência esperada. A aprendizagem individual dos estudantes ocorre de forma idiossincrática, embora frequentemente em caminhos similares. É assumido que uma aprendizagem individual tem alguma regularidade, que a sala de aula limita a atividade matemática frequentemente de formas previsíveis, e que muitos estudantes na mesma sala podem se beneficiar da mesma tarefa matemática. Uma trajetória hipotética de aprendizagem fornece ao professor uma análise racional para escolher um projeto instrucional particular; assim, eu tomo as minhas decisões baseadas nas minhas melhores suposições de como a aprendizagem pode acontecer (SIMON, 1995, p.135).

Simon (1995) pontua que a proposta das Trajetórias Hipotéticas de Aprendizagem tem como pressuposto o processo de construção dos conhecimentos dos alunos sobre o objeto matemático a ser estudado, e que atenda às necessidades e particularidade dos estudantes.

Além de tratar o desenvolvimento das habilidades segundo os eixos temáticos dos Parâmetros Curriculares Nacionais, Brasil (1997) - grandezas e medidas, números e operações, tratamento da informação e espaço e forma - cada unidade das Trajetórias Hipotéticas de Aprendizagem do projeto EMAI inclui “[...] um plano de atividades de ensino organizado a partir da definição de objetivos para a aprendizagem (expectativas) e das hipóteses sobre o processo" (SÃO PAULO, 2013, p.7).

O material do professor do Projeto EMAI contém as sequências propostas para os alunos e os planos de atividades para organização e realização das aulas. Cada sequência didática aponta as expectativas de aprendizagem e atividades diversas. As atividades trazem uma 
conversa inicial a ser mediada pelo professor, uma problematização que visa discussões e socialização entre os alunos e uma intervenção para retomada do conteúdo.

Ainda, é importante que o material didático saiba trabalhar o conhecimento. Neste sentido, Coll (1996) pondera que os conteúdos a serem tratados em sala de aula devem permitir maior compreensão do pensamento e comportamento dos indivíduos. Frente a isto, o autor tipifica que os conteúdos expressos se desmembram nos conteúdos conceituais, procedimentais e atitudinais, ou seja, aqueles que se referem ao que é preciso saber? o que é preciso saber fazer? e o que é preciso ser neste processo?

\section{Procedimentos metodológicos}

A análise do material didático do EMAl se fundamentou na pesquisa documental. Appolinário (2009) aponta que uma pesquisa qualitativa possui estratégia documental se utilizar fontes documentais oriundas de textos escritos ou não escritos, como livros, revistas, documentos legais, arquivos em mídia eletrônica, filmes, slides, fotografias, vídeos. A pesquisa documental recorre a fontes primárias, ou seja, materiais que ainda não receberam tratamento analítico.

Zabala (1998) afirma que as atividades representam o cerne do trabalho didático em uma visão processual da prática em sala de aula. As atividades são:

[...] uma unidade básica do processo de ensino e de aprendizagem, cujas diversas variáveis apresentam estabilidade e diferenciação: determinadas relações interativas professor/alunos e alunos/alunos, uma organização grupal, determinados conteúdos de aprendizagem, certos recursos didáticos, uma distribuição do tempo e do espaço, um critério avaliador; tudo isto em trono de determinadas intenções educacionais, mais ou menos explícitas (ZABALA, 1998, p.17).

Zabala (1998) considera que as sequências didáticas são um “[...] conjunto de atividades ordenadas, estruturadas e articuladas para a realização de certos objetivos educacionais, que têm um princípio e um fim conhecidos tanto pelos professores como pelos alunos" (p.19).

Para o autor, as atividades presentes na sequência didática deveriam: (a) permitir determinar ou colocar em movimento os conhecimentos prévios dos alunos; (b) propor 
conteúdos significativos e funcionais; (c) estar de acordo com o nível de desenvolvimento cognitivo dos alunos; (d) ser um desafio alcançável pelos alunos, fazendo-os adentrar na zona de desenvolvimento proximal e avançar; (e) promover um conflito cognitivo; (f) mobilizar atitudes favoráveis a aprendizagem; (g) promover o aprender a aprender.

De acordo com os pressupostos discutidos anteriormente e o objetivo desta pesquisa, descrevemos abaixo seis categorias para a análise das atividades relativas à habilidade de leitura de horas em relógios digitais e analógicos.

(I.1) Estar em conformidade com as habilidades propostas na Base Nacional Comum Curricular destacadas no Quadro 01.

(I.2) Mobilizar vocabulário para identificar e registrar quantidades por meio de diferentes formas de representação.

(I.3) Apresentar contextos em situações-problema próximos da realidade do aluno.

(I.4) Apresentar contextos da História da Matemática como fonte motivadora para a problematização.

(I.5) Promover ações procedimentais para construir a noção que medir é comparar uma grandeza com uma unidade e expressar o resultado da comparação por meio de um número.

(I.6) Respeitar e permitir o desenvolvimento cognitivo dos alunos.

\section{Descrição e análise das atividades do material didático do Projeto EMAI}

No material didático destinado ao primeiro ano dos anos iniciais do Ensino Fundamental encontramos no projeto EMAI a 'Atividade 15.1' em uma sequência intitulada “Passeio, Compromissos e Tempo". Esta atividade representa o primeiro encontro do material envolvendo o tema 'medida do tempo nos relógios analógicos e digitais'. No protocolo 1 (imagem 01), relativo ao material do professor, são expressas as expectativas de aprendizagem.

Imagem 01: Protocolo 1: as expectativas de aprendizagem da sequência 15 no caderno do professor.

\section{Expectativas de Aprendizagem:}

- Ler tabelas simples.

- Identificar que um dia tem 24 horas.

- Identificar dias da semana, explorando o calendário.

- Identificar dia do mês, explorando o calendário. 
Fonte: São Paulo, 2013, p.97.

No material do professor encontramos a sugestão para se realizar uma leitura coletiva, seguida de uma conversa para sondar o que os alunos conhecem sobre o dia e a subdivisão do mesmo em 24 horas. A seguir, o material propõe uma atividade de sondagem, de modo a prover condições ao professor de verificar se os alunos sabem contar até 24 horas.

Imagem 02: Protocolo 2: uma conversa inicial da atividade 15.1 no caderno do Professor.

\section{Conversa inicial}

Esta é uma atividade de leitura e sugere-se que seja feita coletivamente. Mas, antes de faze-la, pergunte se os alunos sabem quantas horas têm um dia e o que fazem em determinados horários. Verifique se percebem que o dia tem 24 horas e conte com eles de 1 a 24 (relacionando às 24 horas de um dia).

Fonte: São Paulo, 2013, p.97

Em continuação, o referido material traz uma proposta de atividade de exploração inicial, que é denominada de 'Problematização' (imagem 03).

Imagem 03: Protocolo 3: Problematização da Atividade 15.1 no Caderno do Professor.

\section{Problematização}

A partir da leitura do texto faça algumas perguntas às crianças para que comentem o que fazem em alguns momentos do dia. Verifique se, por exemplo, identificam o horário que levantam, horário de almoço, do jantar, horário que vão à escola, horário que vão dormir.

Fonte: São Paulo, 2013, p.97

Por último, o guia sugere ao professor uma etapa que permite aos alunos organizarem os dados, expresso no Protocolo 04. 
Imagem 04: Protocolo 4: Observação/Intervenção da Atividade 15.1 no Caderno do Professor

Observação/Intervenção

Apos o levantamento de horarios. combine com as crianças a organizaçâo de uma tabela Nessa tabela devem constar alguns horarios eo que elas pretendem desenhar. Mais especificamente, o que elas fazem nesse meio tempo. Logo apos, realize uma exposiçào desses desenhos.

\begin{tabular}{|c|c|}
\hline 8 HORAS & \\
\hline 12 HORAS & \\
\hline 19 HORAS & \\
\hline 22 HORAS & \\
\hline
\end{tabular}

Fonte: São Paulo, 2013, p.97

Nesta etapa de desenvolvimento da atividade intitulada "Passeio, Compromissos e Tempo" pudemos observar que as explicações sugeridas para o professor se situam em uma proposta de exploração dos conhecimentos dos alunos nas horas-cheias de um dia, isto é, situadas no universo dos números naturais compreendidos entre zero e vinte e quatro horas.

Porém, percebemos que a atividade não faz menção explícita sobre a fala popular e a convenção cultural de boa parte da humanidade em relação à medida de tempo. No conhecimento cotidiano, o dia é dividido em três períodos: manhã-tarde-noite. Mas, oficialmente, a divisão ocorre em dois períodos: 0 a 12 horas (12 horas é conhecido popularmente no Brasil como 'meio-dia'; 12 até 24 horas (24 horas é a meia-noite). Este conhecimento cotidiano ficou excluído da atividade proposta.

Os alunos normalmente sentem dificuldade nesta transição da linguagem popular para a oficial, como, por exemplo, entender que 'duas horas da tarde' representa oficialmente quatorze horas e que oito horas da noite indicam vinte horas. Este contexto cultural poderia ter sido explorado para permitir um caminho da aprendizagem com base nos conhecimentos prévios dos alunos, de modo a explorar a passagem do conhecimento cotidiano para o conhecimento científico, conforme Vygotsky (1984).

Devemos ressaltar que o material do professor traz a atividade 15.1, do mesmo modo como se encontra no caderno do aluno. A primeira atividade do livro do EMAI dos alunos foca o conceito de horas e se situa na 15a sequência denominada "Passeio, compromissos e tempo", 
conforme aponta a imagem 04.

Imagem 05: Atividade 15.1 no Caderno do Aluno.

\section{SEQUENCIA 15 \\ PASSEIO, COMPROMISSOS E TEMPO}

\section{ATIVIDADE 15.1}

SOFIA GOSTA DE REGISTRAR TUDO EM SEU DIÁRIO. VAMOS LER O TEXTO QUE ELA ESCREVEU NA PRIMEIRA NOITE EM QUE ESTAVA NA PRAIA:

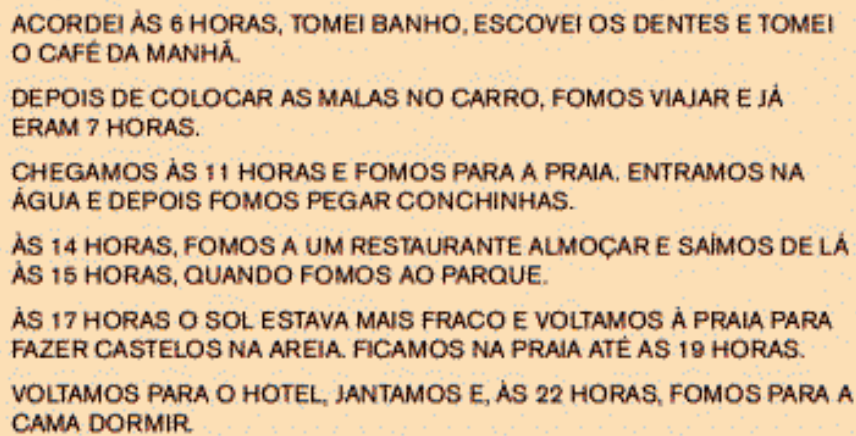

A PARTIR DAS INFORMACOES CONTIDAS NO TEXTO, RESPONDA:

A. QUANTAS HORAS DUROU A VIAGEM?

B. QUANTO TEMPO DEMOROU O ALMOÇO?

Fonte: São Paulo, 2013, p.98

$\mathrm{Na}$ atividade 'Passeio, compromissos e tempo' o objetivo principal expresso no material didático é que o aluno consiga identificar que um dia tem 24 horas através de pequenas atividades em sua rotina diária, tal como expresso nas 'Expectativas de Aprendizagem'.

O material didático solicita um registro das atividades que são desenvolvidas nos horários estipulados. Esta atividade está de acordo com as Orientações Curriculares de Matemática, expresso em São Paulo (2008a), onde se encontra menção de proposição de "[...] situações envolvendo números para que os alunos possam identificar a função que eles desempenham naquele contexto: números para quantificar, números para ordenar, entre outros" (p.28).

Esta situação coaduna com a preocupação de Piaget (1975), onde a noção do conceito de 
tempo seria acessível ao aluno desde as primeiras séries da escolaridade básica, em um contexto de algumas atividades pragmáticas usuais do ser: higiene pessoal, transporte, alimentação e dormir.

Contudo, este problema apresenta um enunciado longo, um enredo não usual em problemas matemáticos, principalmente em se referindo ao 10 ano do Ensino Fundamental. Esta forma exige uma boa compreensão das 'horas-cheias' do dia, algo que necessita ser resgatado pela intervenção do professor. Além disso, a interpretação dos dados do enunciado tem distintos graus de complexidade em relação ao nível cognitivo.

$\mathrm{O}$ item (b) da atividade 15.1 requer que o aluno entenda que o almoço começou às 14 horas e terminou às 15 horas, de modo a que se passou uma hora. As possíveis estratégias que um aluno do 1ㅇano do Ensino Fundamental poderia utilizar são: (a) Realização da contagem desde zero até 15 horas, reforçando as $14 \mathrm{~h}$ e 15h, o que demanda a interpretação conceitual de que entre 14 e 15 horas há um intervalo de 1 hora; (b) Identificação e realização da operação de subtração entre $15 \mathrm{~h}$ e $14 \mathrm{~h}$, resultando um intervalo de exatamente 1 unidade.

Neste mote da atividade pressupõe-se que o processo de contagem já estaria disponibilizado no 10 ano do Ensino Fundamental, em conjunto com as operações de adição e subtração. A Base Nacional Comum Curricular, conforme Brasil (2017) propõe o trabalho com o processo de contagens rotineiras em coleções de objetos e o trabalho com as operações de adição e subtração.

Acreditamos que esta atividade exige apreciável interferência do professor, pois o conhecimento ainda está em fase de construção pelo aluno do 1ำ ano do Ensino Fundamental. Neste sentido, Mix (2010) apontou que algumas crianças na faixa etária de 0 a 6 anos, nos Estados Unidos da América do Norte, podem apresentar habilidades com números, como a contagem antes da escolarização formal. Mas, no Brasil, em escolas de ensino público, acreditamos que estas estão situadas em um contexto cultural-econômico diverso.

Observamos que a situação tem boa formulação, porém representa considerável distância entre o nível de desenvolvimento real (início das contagens e início das operações de adição) e o nível de desenvolvimento proximal (Vygotsky, 1984) das crianças do 10 ano.

No item (A) da atividade 15.1 a complexidade cognitiva é muito grande para um aluno do 10 ano do Ensino Fundamental. Primeiramente, o aluno deverá identificar os dados do início e fim da viagem (que está explícito nos primeiros parágrafos do enunciado). Daí: 11-7 = 4 horas de 
viagem. A análise segue praticamente as mesmas estratégias do item (b).

A proposta seguinte, a Atividade 15.2, está indicada no Protocolo 5 (imagem 06). Consideramos que há uma continuidade com relação à atividade 15.1, ao propor que a partir de figuras que contemplam algumas atividades de lazer, o aluno estipule um horário do dia, tomando como base o diário de Sofia. Nesta, espera-se que a criança identifique que o dia tem 24 horas, conforme previsto na segunda expectativa de aprendizagem.

Imagem 06: Protocolo 5: uma conversa inicial da atividade 15.2 no material do professor

\section{Conversa inicial}

Nesta atividade, são apresentadas ilustraçöes e as crianças devem estabelecer um horário. Na discussăo anterior era estabelecido o horário e elas tinham que desenhar o que comumente fazem nesse horário. Para realizar esta atividade é importante retomar o texto sobre o passeio de Sofia e fazer perguntas: a que horas ela se levantou?, a que horas foi à praia?, a que horas jantou? Se perceber algumas dificuldades por parte das crianças quanto à compreensăo do texto, leia-o novamente para elas. Depois peça para observarem as ilustraçōes do material e preencherem o que se pede.

Fonte: São Paulo, 2013, p.98

A atividade se refere a um tipo de habilidade: relacionar o conhecimento espontâneo ao registro numérico da medida de tempo. A sugestão de conversa inicial do material do professor propõe a retomada da leitura do texto da atividade 15.1, destacando o horário das atividades descritas por Sofia.

Na etapa de problematização o caderno do professor sugere uma intervenção, caso o aluno tenha dificuldade de relacionar as figuras e horários das atividades estipulados pela leitura, conforme destacado na imagem 07.

Imagem 07: Protocolo 6: problematização da atividade 15.2 no material do professor. 


\section{Problematização}

Peça para que observem cada quadrinho, e pergunte a que horas isso aconteceu com base no diário de Sofia.

Socialize as respostas das crianças, observe se há dificuldades e faça as intervençōes. Se for o caso, retome o texto quantas vezes for necessário.

Fonte: São Paulo, 2013, p.98

O material reforça a importância da otimização do tempo para a realização das atividades diárias, e propõe uma atividade extra para a organização da rotina dos alunos, mas não especifica como realizá-la, como apontado no protocolo 7 (imagem 08).

Imagem 08: Protocolo 07: observação/intervenção da atividade 15.2 no material do Professor.

\section{Observação/Intervenção \\ Comente que o diário de Sofia mostra como o tempo foi organizado para a realizaçāo do pas- seio e que em nosso dia a dia também pode- mos organizar nosso tempo para que possamos aproveitá-lo melhor. Proponha que façam um diá- rio contando as atividades que organizaram para serem feitas no próximo domingo.}

Fonte: São Paulo, 2013, p.98

A segunda proposta do livro do EMAI dos alunos apresenta a atividade 15.2 no caderno do aluno (imagem 09).

Esta atividade está parcialmente inserida na preocupação da habilidade EF01MA18, descrita na Base Nacional Comum Curricular, que se refere a "[...] produzir a escrita de uma data, apresentando o dia, o mês e o ano, e indicar o dia da semana de uma data, consultando calendários" (BRASIL, 2017, p.237).

A partir das ilustrações a criança deve estabelecer uma relação para estipular os horários que normalmente são realizadas essas atividades. As crianças deverão utilizar como referência os horários dispostos na atividade anterior ou seu senso comum ao indicar as horas, que resgata os conhecimentos espontâneos da criança. 


\section{ATIVIDADE 15.2}

COM BASE NO DIÁRIO DE SOFIA, ESCREVA PARA CADA ILUSTRAÇÃO UM POSSIVELL HORÁRIO A QUE ELA SE REFERE.
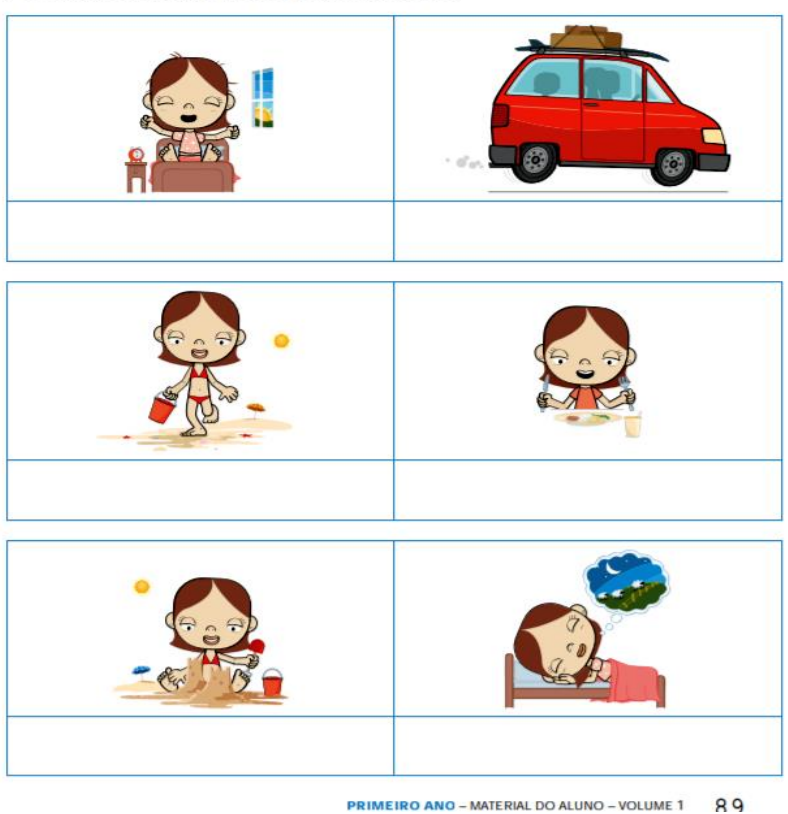

Fonte: São Paulo, 2013, p.98

Observamos que a atividade proporciona registros breves - as representações figurais de modo que o aluno possa apreender a cronologia dos acontecimentos do dia, algo não explícito nas fases das Trajetórias Hipotéticas de Aprendizagem.

Segundo Vygotsky (1984), a construção do conceito científico ocorre durante o processo de ensino, através de atividades estruturadas e, pela mediação do professor que atribui conceitos mais formais, exigindo uma abstração maior do indivíduo e conceitos mais definidos do que os construídos espontaneamente.

Na Ficha 01 (quadro 2) realizamos uma síntese das Atividades 15.1 e 15.2 presentes no Caderno do aluno, de acordo com as categorias elencadas. 
Quadro 2

\begin{tabular}{|l|c|c|c|}
\hline \multicolumn{1}{|c|}{ Ficha 01: Síntese das categorias relativas as atividades 15.1 e 15.2 } & Sim & Não & Parcial \\
\hline $\begin{array}{l}\text { Está em conformidade com as habilidades propostas na Base } \\
\text { Nacional Comum Curricular destacadas no Quadro 01. }\end{array}$ & $\mathrm{X}$ & \\
\hline $\begin{array}{l}\text { Mobiliza vocabulário para identificar e registrar quantidades por } \\
\text { meio de diferentes formas de representação. }\end{array}$ & & $\mathrm{X}$ \\
\hline $\begin{array}{l}\text { Apresenta contextos em situações-problema que estão próximos da } \\
\text { realidade do aluno. }\end{array}$ & $\mathrm{X}$ \\
\hline $\begin{array}{l}\text { Apresenta contextos da História da Matemática como fonte } \\
\text { motivadora para a problematização. }\end{array}$ & $\mathrm{X}$ & \\
\hline $\begin{array}{l}\text { Promove ações procedimentais para construir a noção que medir é } \\
\text { comparar uma grandeza com uma unidade e expressar o resultado } \\
\text { da comparação por meio de um número }\end{array}$ & $\mathrm{X}$ & \\
\hline Respeita e permite o desenvolvimento cognitivo dos alunos & & $\mathrm{X}$ \\
\hline
\end{tabular}

Fonte: Os autores

No primeiro ano, o caderno do aluno não propõe nenhuma atividade que envolva o relógio analógico ou digital ou qualquer outro instrumento para a contagem de horas. Em ambas as atividades expostas, o aluno trabalha a relação das horas com as atividades do cotidiano.

\section{Conclusões}

Percebemos que as duas atividades propostas para o $1^{\text {o }}$ ano do Ensino Fundamental envolvendo o tema 'medida do tempo' buscaram apoio nas Trajetórias Hipotéticas de Aprendizagem. Em ação, a proposta é sedimentada por meio da estruturação 'Conversa Inicial', 'Problematização', 'Observação e Intervenção' seguida da atividade a ser realizada pelos alunos como forma de aprendizagem.

As duas sequências do 10 ano do Ensino Fundamental analisadas contam com uma conversa inicial, de modo que o professor possa prever as habilidades esperadas a serem desenvolvidas em relação aos conhecimentos dos alunos, descritas por objetivos de aprendizagem.

Neste contexto, as etapas de 'Problematização' e 'Observação e Intervenção' expressam 
possibilidades de se colocar o aluno em ação. Para que tal dinâmica ocorra, a mediação do professor é essencial durante o processo, de modo a viabilizar que o aluno se situe em uma zona de desenvolvimento proximal, aos moldes das ideias de Vygotsky $(1984 ; 1987)$.

Para guiar tais ações docentes o projeto EMAl dispõe de orientações ao final de cada unidade do material do professor. Alguns destes procedimentos incluem a análise das propostas de atividades e planejamento na rotina semanal, escolha de outros materiais utilizados para consulta, seleção de atividades que complementem a atividade com os alunos, leitura dos textos dos livros com os alunos, elaboração de lições simples e interessantes para casa por fim, a organização do material produzido pelas crianças em um portfólio para registro do desempenho e avanços da sala.

Ainda, o material didático do Projeto EMAI permite, em parte, colocar em movimento os conhecimentos anteriores dos alunos, pois os conceitos envolvidos são de natureza empírica, que podem ter sido experenciados pelos alunos no ambiente da cultura. Neste sentido, cabe ao professor observar e realizar intervenções diante das manifestações dos alunos.

Com relação ao desenvolvimento de conteúdos procedimentais, conforme Coll (1996), as duas atividades remetem somente a cálculos aritméticos, ligadas ao cotidiano, mas estão situadas em um plano mais ligado a cognição, envolvendo pouca manipulação de materiais concretos ou atividades práticas.

As atividades são um desafio alcançável pelos alunos e situadas em contextos simples e próximos a realidade do aluno, em ilustrações ligadas a cultura atual.

Quanto aos aspectos da História da Matemática como problemática observamos a quase ausência deste importante referencial para a elaboração de situações no tocante ao tema 'medida de tempo' nas duas atividades propostas do 10 ano.

Apesar de inúmeras pesquisas na área da História da Matemática, a própria Base Nacional Comum Curricular para o Ensino Fundamental acabou não realçando este recurso como fonte de enriquecimento do trabalho pedagógico para o professor da escolaridade básica.Ainda, nas grades curriculares das licenciaturas em Matemática no Brasil o oferecimento da História de Matemática como disciplina ainda não está consolidado, o que poderia incrementar a formação do futuro professor.

Por último, devemos ressaltar que o material didático foi elaborado anteriormente ao 
anúncio da Base Nacional Comum Curricular, descrito em Brasil (1997). Porém, as habilidades descritas (EF01MA16; EF01MA17; EF01MA18) estão presentes nas duas atividades propostas, porém estão desenvolvidas de modo muito pontual, sem maiores desdobramentos. Ademais, os enunciados das atividades requerem o auxílio do professor, pois estão acima da capacidade cognitiva de um aluno da primeira série do Ensino Fundamental.

\section{Referências}

APPOLINÁRIO, F. Dicionário de metodologia científica: um guia para a produção do conhecimento científico. São Paulo, Atlas, 2009.

BRASIL. Parâmetros curriculares nacionais: ensino fundamental. Brasília: MEC, 1997.

BRASIL. Base nacional comum curricular: educação é a base. Brasília: Ministério da Educação, 2017. Disponível em: http://basenacionalcomum.mec.gov.br/wp-

content/uploads/2018/02/bncc-20dez-site.pdf. Acesso em: 21 dez. 2017.

CARAÇA, B. J. Conceitos fundamentais da matemática. 5.ed. Lisboa, Portugal: Bertrand (Irmãos) Ltda. 1970.

COLL, C. Os componentes do currículo. In: COLL, C. Psicologia e currículo. São Paulo: Ática, 1996, p.65-152.

MIX, K. S. Habilidades iniciais em operações com números: a transição dos primeiros meses de vida até a primeira infância. 2010. Disponível em: http://www.enciclopediacrianca.com/operacoes-com-numeros/segundo-especialistas/habilidades-iniciais-emoperacoes-com-numeros-transicao. Acesso em: 29 dez. 2018.

MIZUKAMI, M. G. N. Ensino: as abordagens do processo. São Paulo: EPU, 1986.

NOGUEIRA, I. C. Como vai o tempo no 10 ciclo? Revista Cadernos de Estudo, Porto: ESEF de Paula Frassineti, n.4, p.73-82, 2006.

PERRENOUD, P. Construir as competências desde a escola. Porto Alegre: ArtMed, 1999.

PIAGET, J. A noção de tempo na criança. Rio de Janeiro: Record, 1975.

SANTOS, A. J. P. A gestão do tempo nos tempos educativos do 1ำ ciclo do ensino básico. Saber e Educar. n.21, p.51-65, 2016.

SÃO PAULO. Orientações curriculares do estado de São Paulo: língua portuguesa e matemática - 
Ciclo I. São Paulo: FDE, 2008a.

SÃO PAULO. Proposta curricular do estado de São Paulo: matemática. São Paulo: SEE, 2008b.

SÃO PAULO. EMAI: Educação Matemática nos anos iniciais do ensino fundamental; organização dos trabalhos em sala de aula, material do professor - primeiro ano. São Paulo: SEE, 2013.

SIMON, M. A. Reconstructing mathematics pedagogy from a constructivist perspective. Journal for Research in Mathematics Education.v.26, n.2, p.114-145, 1995.

VYGOTSKY, L. S. A formação social da mente. São Paulo: Martins Fontes, 1984.

VYGOTSKY, L. S. Pensamento e linguagem. São Paulo, Martins Fontes, 1987.

ZABALA, A. A prática educativa: como ensinar. Porto Alegre: ArtMed, 1998.

Recebido outubro 2019.

Aprovado março 2020. 